\title{
Systemic complications in the hormonal treatment of prostate and breast cancer
}

\author{
Beata Jagielska ${ }^{1}$, Grażyna Poniatowska ${ }^{2}$, Konrad Tałasiewicz ${ }^{1}$, \\ Tomasz Demkow ${ }^{2}$, Paweł Wiechno
}

Oncological treatment is often associated with a wide range of adverse effects. The article focuses on systemic complications that may occur during the hormonal therapy of prostate and breast cancer. Considering that current treatments are increasingly effective, the number of patients suffering from early and remote complications of cancer therapy can be expected to rise. Many undergo radical treatment and in this group in particular, close attention should be paid to the prevention, early diagnosis, and treatment of adverse effects. Hormonal disorders and their complications considerably affect the quality of life and life expectancy by upsetting general systemic homeostasis.

NOWOTWORY J Oncol 2017; 67, 3: 206-214

Key words: aromatase inhibitors, tamoxifen, androgen antagonists, side effects of medication, prostate cancers, breast cancers

\section{Hormonal therapy of patients with prostate cancer}

The incidence rate of prostate cancer is rapidly on the rise both in Poland and beyond as a side effect of increasing life expectancy and a significant improvement in detection methods. According to the National Cancer Registry, over 12 thousand new cases were diagnosed in Poland in 2013, which represents more than a twofold increase over the last decade. Prostate cancer is the second most frequent cancer and the third most frequent cause of cancer death in the male population. Over the last decades, a significant improvement has been observed both in radical therapy and in the treatment of systemic disease. As a consequence, there has also been a systematic growth in the number of prostate cancer patients who survive over many years; for these individuals, the quality of life is of paramount importance and it is largely determined by the presence of treatment-related adverse effects, some caused by hormonal therapy.

Prostate cancer is an androgen-dependent condition. Androgens are secreted primarily by the testicles, which produce nearly $95 \%$ of these hormones; the remaining $5 \%$ are generated by the adrenal glands. The androgen-dependence of prostate cancer makes hormonal therapy one of the most effective treatment methods. It may involve surgical castration (bilateral orchiectomy), pharmacological castration (GnRH agonists or antagonists), steroid receptor blocking with antiandrogens, or androgen biosynthesis inhibition. The objective of hormonal therapy is to inhibit the progression-stimulating impact of androgens on cancer-cell receptors. The desired effect may be achieved by lowering the concentration of androgens in the system or blocking the androgen receptor. In patients with systemic disease, hormonal therapy is continued until disease progresses or unacceptable toxicity symptoms set in, which often means many years or even a lifetime on medication. Locally advanced disease is treated with hormonal therapy in sequence with radiotherapy or surgery. In these cases, the time of exposure to hormonal drugs is limited. The basic adverse effects of hormonal therapy in prostate cancer patients are directly related to androgen deficiency, which adversely

\footnotetext{
${ }^{1}$ Department of Diagnostic Oncology and Cardioncology, Maria Skłodowska-Curie Memorial Cancer Centre
} and Institute of Oncology, Warszawa, Poland

${ }^{2}$ Department of Urology, Maria Skłodowska-Curie Memorial Cancer Centre and Institute of Oncology, Warszawa, Poland 
affects the quality of life and induces secondary complications that may lead to disease and even death.

Early symptoms of androgen deficiency include: fatigue, hot flushes, gynecomastia, hair loss, increased fatty tissue, bone loss, lipid disorders, hyperinsulinemia, and loss of libido or erectile dysfunctions. Sleep and memory disorders may also occur, and in extreme cases, low mood associated with treatment may lead to depression.

Late symptoms include osteoporosis, type 2 diabetes, the metabolic syndrome $X$, and cardiovascular conditions.

The specific profile of adverse effects depends on the method of hormonal treatment. Unlike surgical and pharmacological castration, non-steroid antiandrogens do not lower the concentration of testosterone, which allows patients to maintain sexual activity, as well as reduces the risk of atherosclerosis and metabolic complications. In comparison with other hormonal methods, the treatment has a positive effect on the quality of life, especially at a younger age, and lowers the risk of treatment-related conditions. It should be kept in mind, however, that its effectiveness will resemble that of pharmacological castration only in monotherapy with high doses of bicalutamide (150 mg per day). In patients with prior cardiovascular disease, extreme caution is advisable during the long-term administration of LHRH analogues. Bicalutamide at a daily dose of $150 \mathrm{mg}$ may be considered on the basis of EPC test results [1,2]. This course of treatment, however, is not recommended for routine use in clinical practice [3].

Drugs from the group of GnRH agonists result in a fleeting rise in testosterone levels, which increases pain and raises the risk of spinal cord compression and urine retention in advanced cancer patients. Administering anti-androgens at least 3 days before the introduction of the LHRH analogue reduces but does not eliminate the risk of these events.

Table I. Androgen deficiency complications

\begin{tabular}{l}
\hline Androgen deficiency complications \\
\hline Early: \\
Fatigue \\
Hot flushes \\
Sexual disorders (loss of libido, erectile dysfunction) \\
Gynecomastia, mammary gland pain \\
Hair loss \\
Increased fatty tissue; bone loss \\
Lipid disorders (increased cholesterol, LDL and TG; reduced HDL) \\
Hyperinsulinemia \\
Sleep and memory disorders \\
Low mood, depression \\
Late: \\
Osteoporosis, bone fractures \\
Type 2 diabetes \\
Metabolic syndrome \\
Cardiovascular conditions \\
Ischemic heart disease, heart attack \\
Venous thromboembolism, pulmonary embolism, brain stroke \\
\hline
\end{tabular}

The administration of GnRH antagonists causes an immediate testosterone suppression, and, in comparison with agonists, drugs from this group are twice more likely to cause cardiovascular complications. For this reason, caution is recommended while qualifying patients with prior cardiac disorders for hormonal therapy in general, and with the use of $\mathrm{GnRH}$ antagonists in particular.

\section{Hot flushes and gynecomastia}

Hot flushes occur in as many as $75 \%$ of patients undergoing hormonal therapy for prostate cancer [4].Even though the symptom does not affect the overall survival rate, it does have a significant impact on the quality of life. Hot flushes result from malfunctions in hypothalamic thermoregulatory centers, which are caused by androgen deficiency. By inhibiting the secretion of the luteinizing hormone (LH), cyproterone acetate may help reduce these sensations during hormonal therapy with LHRH analogues. Parallel treatment with cyproterone acetate and medroxyprogesterone acetate was studied in a randomized double-blind clinical trial, which showed that the combination of the two drugs leads to a considerable reduction in hot flushes after 4 weeks of treatment [5]. Another trial demonstrated that the administration of gabapentin during hormonal therapy reduces hot flushes by $50 \%$ [4].

\section{Impaired cognitive function; low mood and depression}

Nelson et al. showed that $47-69 \%$ of patients treated with hormonal therapy experience a deterioration in at least one cognitive function [6]. It should be kept in mind, however, that treatment-related fatigue and hot flushes as such may also affect cognitive functioning. Treatment may affect short-term and spatial memory. Carrier et al. observed a significantly lower mood, greater irritability, and depression in patients treated with hormonal therapy [7], while Lee et al. recorded that they were considerably more likely to suffer from depression than the untreated group and the control group of healthy men [8].

Not all complications subside after the end of adjuvant hormonal treatment.

\section{Metabolic complications of hormonal therapy}

At physiological concentrations, androgens help maintain the normal state of homeostasis in the body; they contribute to the growth of bones and muscles and and decrease the fatty tissue. Hormonal therapy, however, has the opposite effect. An increase in fatty tissue leads to insulin-resistance and, as a consequence, to the development of diabetes, lipid disorders, hypertension, and cardiac complications. The co-morbidity of obesity, hypertension, diabetes, and lipid disorders is defined as the metabolic syndrome (Fig. 1). 
In the Polish population, the metabolic syndrome affects c. $20 \%$ of adults ( $22 \%$ of women and $18 \%$ of men), and its incidence rate increases with age. It is estimated to occur in c. 5.7 million people in Poland and significantly increases the risk of atherosclerosis and cardiovascular disease [9].

Prostate cancer patients treated with radiotherapy combined with adjuvant hormonal therapy, regardless of the length of treatment, are twice more likely to be diagnosed with the metabolic syndrome than patients treated with radiotherapy alone [10].

Morote et al. observed a significant rise in individual components of the metabolic syndrome: abdominal obesity, BMI disorders, glucose, triglycerides and cholesterol in prostate cancer patients treated with hormonal therapy. The incidence of a full-blown metabolic syndrome has not been observed to grow significantly over the term of twelve months [11].

Smith et al. determined that GnRh agonists increase fatty tissue, insulin resistance, and triglyceride levels [12]. Unlike the classical metabolic syndrome, the administration of GnRH agonists is associated with an increase of subcutaneous fatty tissue, HDL levels, and adiponectin [13].

Hormonal therapy induces the growth of fat cells; this fuels the production of protein molecules known as adipokines, which lead to the gradual atrophy of muscle tissue. The latter, through myokines, further increases the volume of fatty tissue and leads to bone loss. These interactions are further associated with increased insulin resistance, which raises the risk of type 2 diabetes, lipid disorders, and cardiovascular complications.

Primary hormonal therapy of prostate cancer patients increases the risk of diabetes by $60 \%$ [14]. Type 2 diabetes is more frequent during long-term hormonal therapy as compared with untreated control groups (44\% vs $12 \%$ ) [15].

Low testosterone levels strongly correlate with the risk of the metabolic syndrome, regardless of BMl; the risk is 2.7 times greater [16].

\section{Cardiac complications}

Whether the risk of cardiovascular disease is higher in patients treated with hormonal therapy remains controversial. Some studies indeed show a greater incidence of ischemic heart disease, heart attack, and arrhythmias [17-22].

In a special population-based study, Keating et al. determined that treatment with $\mathrm{GnRH}$ agonists involves a significantly higher risk of diabetes and cardiovascular complications (ischemic heart disease, heart attack, cardiac arrest and stroke) [23], but other studies have failed to confirm a statistically significant correlation [24-26].

In a metaanalysis of 8 randomized trials, Nguyen et al. did not observe a heightened risk of cardiovascular complications in short-term (under 6 months) or long-term (more than 3 years) hormonal therapy [27]. In comparison with radiotherapy alone, short-term adjuvant hormonal treatment following radical radiotherapy does not seem to increase the risk of these events [28].

\section{Osteoporosis}

Hormonal therapy reduces the mineral density of bones, leads to the development of osteopenia and osteoporosis, and increases the risk of pathological fractures.

As many as $40 \%$ of patients suffer from osteopenia, and $11 \%$ - from osteoporosis [29], even before the beginning of hormonal treatment. Prostate cancer usually affects older

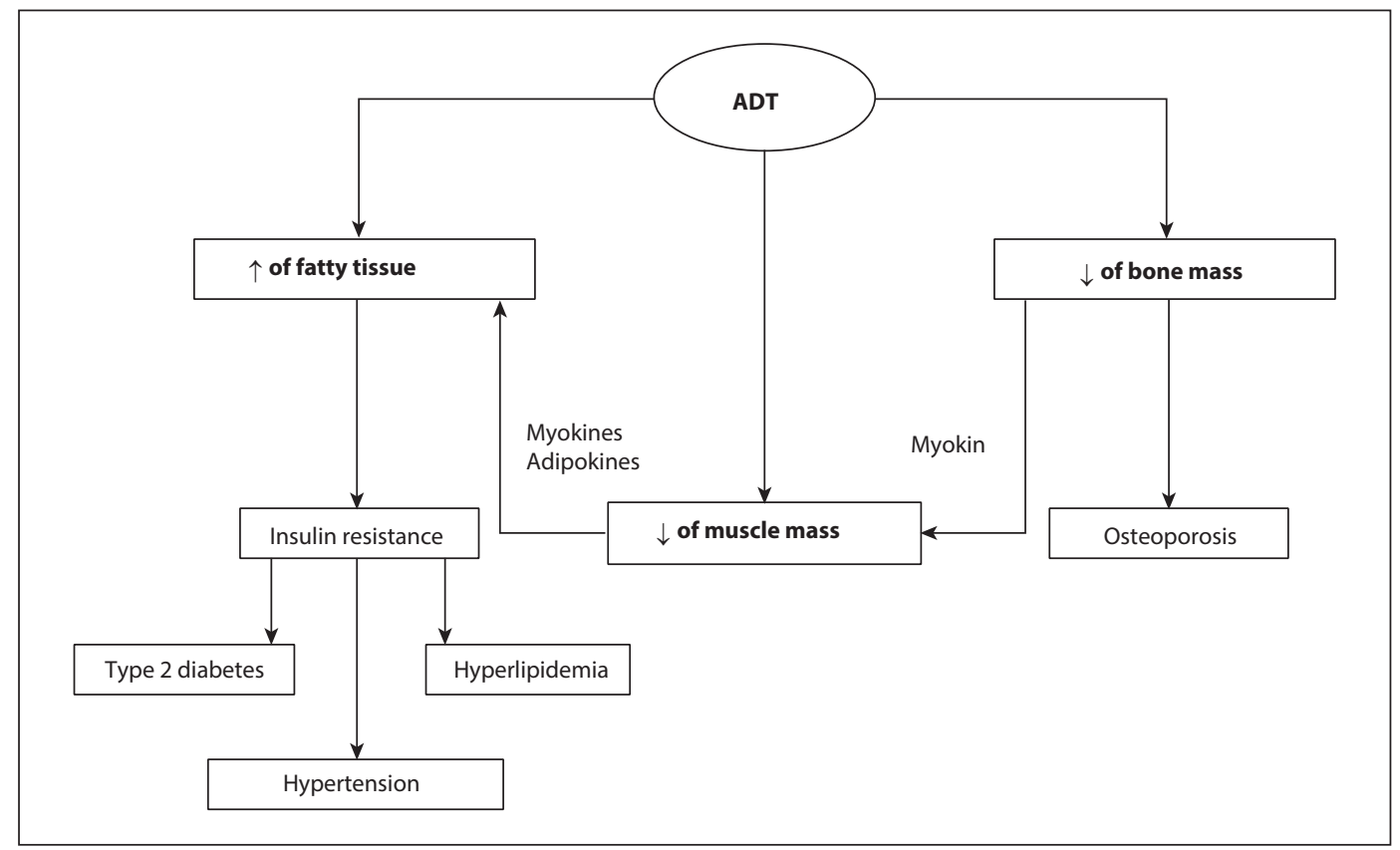

Figure 1. Metabolic complications of androgen deprivation therapy (ADT) 
patients and the loss of bone mass is related to the normal physiological ageing process.

During hormonal therapy, the annual loss of mineral density amounts to $2-8 \%$ in the lumbar section of the spine and $1.8-6.5 \%$ in the neck of the femur [30].

The incidence rate of osteoporosis increases from 36 to $80 \%$ after 10 years of hormonal therapy, and after that, osteopenia or osteoporosis can be expected to develop in all treated individuals [31].

Bone complications are diagnosed in c. $49 \%$ of prostate cancer patients with bone metastases. Hormonal therapy increases the risk of these complications due to its negative effect on mineral density [32].

The remodeling of bone tissue is a process that lasts over a lifetime. In adults, c. $10 \%$ of the total bone mass is remodeled within a single year. A proper balance between the processes of osteogenesis and resorption helps preserve the normal structure of the bone system; such balance is maintained thank to the RANKL/RANK/OPG pathway. To prevent bone complications in hormonal therapy, zoledronic acid (from the bisphosphonate group) or a monoclonal antibody, denosumab, may be used. It is also essential to administer calcium and vitamin D3 supplements.

Bisphosphonates are absorbed by the calcium-rich bone tissue by binding with calcium ions and stored in the bone tissue until absorbed by osteoclasts in the endocytic process, which causes these cells to undergo apoptosis. A metaanalysis that studied the effectiveness of bispohosphonates in hormonal therapy of prostate cancer showed a significant reduction in the risk of fractures and osteoporosis. The greatest effectiveness was associated with zoledronic acid, which has been registered for use in the prevention of bone complications in patients with bone metastases [32, 33].
Denosumab is a human monoclonal antibody directed against the RANK receptor ligand. By binding to RANKL, it neutralizes the ligand and prevents its attachment to RANK and the differentiation of osteoclasts, which consequently inhibits bone resorption. Denosumab can be used to prevent the loss of bone mass in the course of hormonal ablation in prostate cancer patients at a higher risk of fractures (age $>70$ years or $<70$ years with the BMD T-score in the lumbar section of the spine, hip, or neck of the femur $<-1.0$ or osteoporotic fracture in the interview). The effectiveness of the drug was demonstrated in the HALT clinical trial: denosumab helped increased mineral density and reduced the risk of new fractures by $62 \%$ after 3 years of use [34].

Selective estrogen receptor modulators (SERMs) also help reduce bone loss by $50 \%$ after 2 years of treatment $[35,36]$.

\section{Systemic complications of hormonal treatment in women}

The beginnings of breast cancer treatment date back to the $19^{\text {th }}$ century, when surgical oophorectomy was first introduced as a therapy. Systematic advancement and development of molecular biology helped to determine the role of estrogen and progesterone receptors in the progression of the disease, which meant that hormonal treatment could be applied in routine medical practice. Hormonal therapy inhibits the systemic impact of estrogens and progestogens on cells, including cancer cells, that express relevant hormonal receptors. Estrogens can be blocked by inhibiting gonadotropins or removing their source (e.g. by the use of LHRH agonists, hypophysectomy), blocking the estrogen receptor, or inhibiting the peripheral synthesis of estrogen precursors, i.e. androgens (Fig. 2) [37, 38].

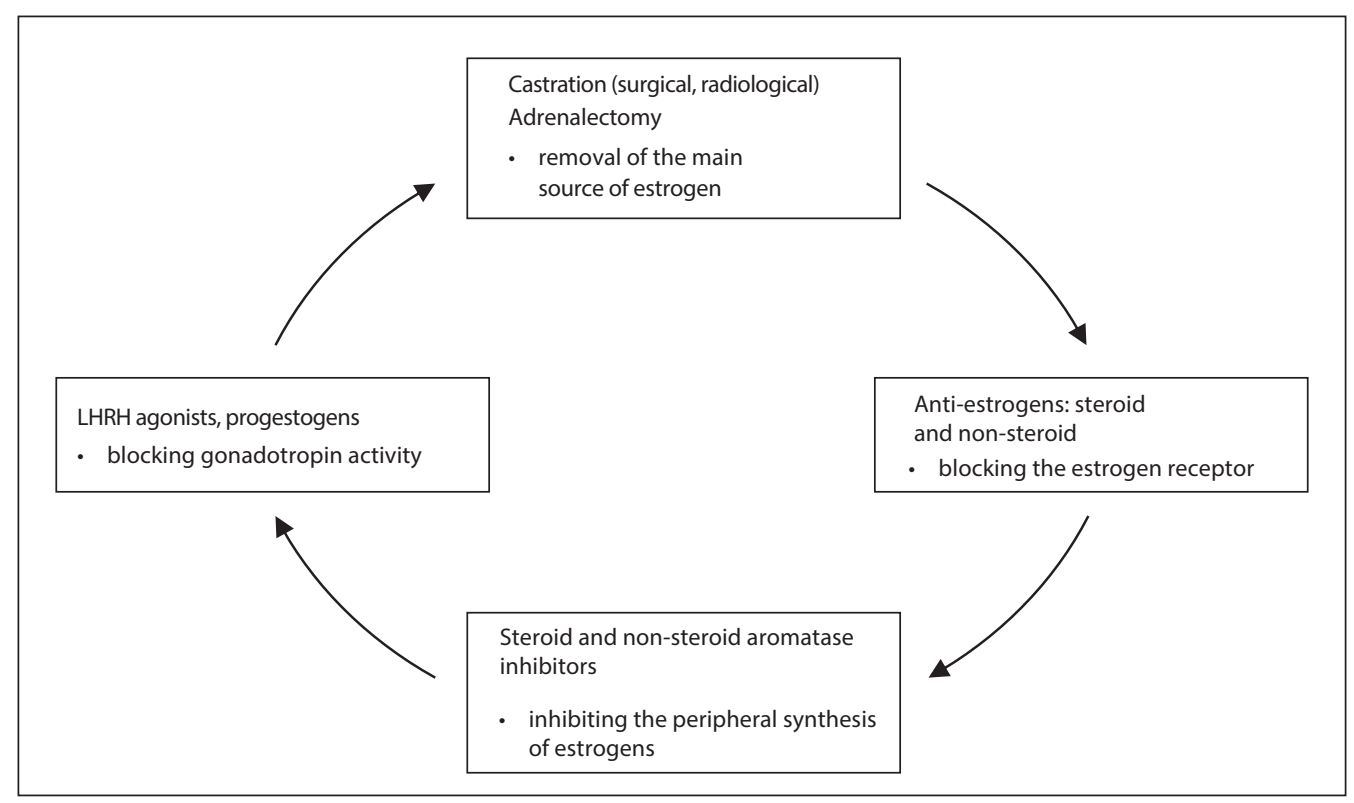

Figure 2. Hormonal therapy — mechanism of action 
Tamoxifen is the oldest drug used both in adjuvant therapy, and in patients with advanced breast cancer. Classified as a non-steroid anti-estrogen - selective estrogen receptor modulator (SERM), the substance has an agonistic effect on estrogen receptors. Its efficacy crucially depends on the transformation of the prodrug into its active form, which, according to the relevant literature, shows a 30-100 greater anti-estrogen activity. Tamoxifen is metabolized in the liver by the cytochrome P450 enzyme system into endoxifen or 4-hydroxytamoxifen [39-42], and many isoforms of the cytochrome P450 enzymes are known to be involved in the process. It should be noted, however, that its actual clinical effectiveness depends on the concentration of endoxifen in the cytoplasm. Literature suggests that patients treated with tamoxifen show higher levels of endoxifen than of 4-hydroxytamoxifen. Endoxifen degrades the estrogen receptor by proteasomes, whereas 4-hydroxytamoxifen and $\mathrm{N}$-desmethyl tamoxifen stabilize it $[40,43,44]$.

Drugs from the aromatose inhibitor (AI) group can be divided in terms of chemical structure into steroid inhibitors (anastrozole and letrozole) and non-steroid inhibitors (exemestane), and their role is to inhibit the process by which androstendion is transformed into estrogen, occurring primarily in the fatty tissue, liver, adrenal glands, muscles, and glandular breast tissue. The inhibition of the aromatization process is estimated to reduce estrogen to undetectable levels. It should be kept in mind, however, that the effects of Als are selective and reversible for steroid inhibitors, but irreversible for non-steroid types [37, 38].

In order to prevent the spread of the disease, breast cancer patients of premenopausal age undergo surgical castration or hormonal therapy based on LHRH analogues. Systemic treatment has similar therapeutic outcomes with the sole difference that, unlike surgery, it is reversible. LHRH analogues affect the function of the hypothalamic-pituitary system. Initially, i.e. for a period of about two weeks, FSH and LH concentration in the blood increase; subsequently, as a consequence of the the feedback mechanism, their secretion is inhibited and ovary function decreases, resulting in a drop in estrogen levels [37, 38].

Due to their impact on the entire organism, adverse side-effects may affect many organs and depend on the type of drug used in treatment.

\section{Low estrogen symptoms}

One of the most frequent adverse effects of SERMs (selective estrogen receptor modulators) includes vasomotor symptoms, which occur regardless of the age of the patient [37]. Literature indicates that approximately two thirds of all patients suffer from hot flushes, while $44 \%$ experience nocturnal sweating and sleep disorders [46]. Couzi et al. showed that out of 190 breast cancer patients of post-menopausal age, approximately $2 / 3$ suffered from hot flushes. $29 \%$ rated their intensity as low and $37 \%$ as medium; the remaining $34 \%$ of women experienced severe symptoms [47]. Carpenter observed hot flushes in $65 \%$ patients in a group of 114 women (with the median age of 58.8) who had completed radical treatment and were put on adjuvant tamoxifen-based therapy. Of all women included in the study, 59\% described their symptoms as severe. Hot flushes were more frequent in patients treated with tamoxifen alone (72\%) and those receiving chemotherapy (78\%) [48].

Literature suggests that a drop in estrogen levels leads to the malfunctioning of the hypothalamic thermoregulatory center, peripheral circulation, and perspiration. Animal testing demonstrated that disturbances in norepinephrine secretion in the hypothalamus may affect the thermoregulatory center and intensify hot flushes. It is often emphasized that the stimulation of the serotonin receptor $5-\mathrm{HT} 2 \mathrm{a}$ induces hyperthermia, while the stimulation of 5-HT1a lowers body temperature. The influence of estrogens on the expression and activation of $5-\mathrm{HT}$ receptors has not been entirely explained $[49,50]$. The results of the ZEBRA clinical trial, which studied 1640 patients, showed that those treated with goserelin for two years experienced an increase in the intensity of hot flushes, which subsided once the drug was discontinued [51]. In another clinical trial, where 149 patients were randomly assigned to four groups (treated with goserelin, tamoxifen, tamoxifen and goserelin, and a control group, respectively), increased vasomotor symptoms were observed in groups treated with goserelin and goserelin and tamoxifen, as compared to the control group [51].

Clinical trials indicate that hot flushes and other vasomotor symptoms related to aromatase inhibitors (Als) are not very severe. An experiment with 4742 breast cancer patients randomly assigned to the five-year adjuvant therapy with tamoxifen or exemestane (a steroid aromatase inhibitor) showed no differences between the two groups in terms of vasomotor effects after two years; the figures were $39.6 \%$ and $42 \%$, respectively [52]. Another trial with 5187 breast cancer patients treated with letrozole or placebo, following a five-year tamoxifen-based therapy, demonstrated a significant intensification of hot flushes in the letrozole group (47.2\%) as compared to the control group (40.5\%). $4.5 \%$ of patients discontinued treatment with letrozole because of these side effects, while the corresponding figure for the placebo group was $3.6 \%$. The difference was not statistically significant [53].

\section{Treatment of vasomotor symptoms}

The treatment of vasomotor symptoms induced by hormonal therapy can be difficult. Some authors recommend dietary modifications, such as increasing the intake of spicy food, coffee, black tea, or black cohosh. Clonidine, bromocriptine, and vitamin E were not shown to be effective. It would seem that optimal outcome is ensured by the 
simultaneous use of selective serotonin reuptake inhibitors (SSRIs) and selective norepinephrine reuptake inhibitors (SNs). Some authors report that c. $25 \%$ of patients treated with tamoxifen also takes drugs from the SSRI group, such as fluoxetine, paroxetine or venlafaxine. It should be kept in mind, however, that some might enter into various interactions and affect CYP2D6 metabolism, which may lead to a decrease in the concentration of endoxifen, the active metabolite of tamoxifen, and thus reduce treatment efficacy. It is believed that drugs from the fluoxetine and paroxetine group are strong CYP2D6 enzyme inhibitors. Weak inhibitors include sertraline, citalopram, and venlafaxine [48].

In a study devoted to the determinants of tamoxifen-based treatment in breast cancer, Wieczorek quotes the results of a trial presented at the Congress of the American Society of Clinical Oncology (ASCO) in 2009, which showed that the two-year risk of relapse in a group of patients treated with tamoxifen alone equaled $7.5 \%$, while the corresponding figure for a group in which the drug was combined with a strong CYP2D6 inhibitor was $13.9 \%$. These data were not confirmed by the analysis of the Dutch PHARMO database conducted by Dezentje, but it should be noted that the median treatment time in Aubert's trial was 255 days, as compared to only 60 in the Dutch study, which may have influenced the final results [40].

\section{Quality of life}

Hormonal treatment inarguably affects the quality of life of breast cancer patients, changing variables such as emotional state (inducing low mood, anxiety disorders, and depression), sexual function, and causing fatigue. It is often difficult to tell whether these events are the consequence of the cancer or its treatment. In 1998, Carpenter concluded that the presence of vasomotor symptoms only marginally reduces the quality of life [46], but subsequent observations clearly confirmed a significant drop in QoL parameters in breast cancer patients with postmenopausal symptoms [48]. In a clinical analysis designed to assess the impact of vasomotor symptoms on breast cancer patients, Stein observed a much higher incidence of fatigue and sleep disorders in women of postmenopausal age. It should be noted, however, that the application of the study was limited, because of the relatively small size and homogeneity of the study group [54]. Mourits, on the other hand, demonstrated that tamoxifen had a negative impact on libido and sexual activity, causing vaginal dryness in $40 \%$ and dyspareunia in $30 \%$ of patients (Fig. 3) [54-56].

\section{Bone and joints disorders. Bone mineral density (BMD) disorders}

BMD disorders are one of the more frequent adverse effects of hormonal therapy. Their intensity depends on the type of treatment and patient age, e.g. postmenopausal women treated with tamoxifen actually experience an improvement in bone density and a lower risk of fractures, while in premenopausal subjects bone loss not only during treatment with tamoxifen but also after pharmacological or surgical oophorectomy.

Increased density loss, up to $17.3 \%$ over 3 years, is observed in postmenopausal women treated with aromatase inhibitors, and bilateral oophorectomy reduces bone mass to c. $20 \%$ within 18 months. The process progresses over time. In contrast, bone loss in healthy postmenopausal patients is not greater than 3\% per year. The risk of fractures in postmenopausal patients treated with aromatase inhibitors is estimated to be more than $30 \%$ greater than in healthy women of similar age [57]. Hadiji indicates that the loss of bone density in healthy postmenopausal women equals c. $1 \%$ per year, as compared to $2 \%$ for Al-treated patients [58].

The mechanism responsible for the loss of bone density as a result of $\mathrm{Al}$ treatment is the dysfunction of the RANK pathway. The RANK pathway controls the processes of bone remodeling, i.e. resorption and stratification, based on elements such as the receptor activator of nuclear factor $N F-\kappa B$ (RANK), receptor activator of nuclear factor NF- $\kappa \mathrm{B}$ ligand (RANKL), and osteoprotegerin (OPG) $[37,38]$. The role of cytokines (IL-1 $\alpha$, IL-6, IL-11, TNF- $\alpha$ ) and glucocorticosteroids is also important. The activation of the RANK pathway is conditioned by the activity of the ligand on the surface of osteoclasts, which activates the processes that stimulate their survival and maturation [59].

It cannot be ruled out that the greater incidence of bone events during treatment with aromatase inhibitors has to do not just with the drug, but also with the fact that the therapy is primarily used in women over the age of 50, when physiological menopause steps up the processes of bone loss.

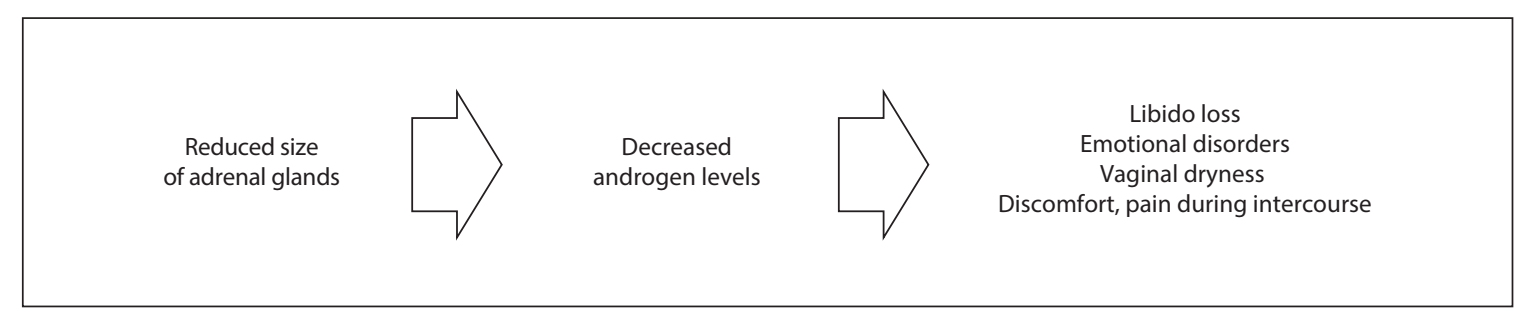

Figure 3. Libido disorders 
Based on a large prospective clinical trial with postmenopausal breast cancer patients treated with Als, Hadji showed that the most important risk factors of bone fracture included $\mathrm{Al}$ intake, $\mathrm{T}$ score $<1.5$, age $>65$ years, reduced BMI $\left(<20 \mathrm{~kg} / \mathrm{m}^{2}\right)$, bone brittleness after age 50, a family history of hip fracture, oral administration of corticosteroids over a period of more than 6 months, and tobacco use. The T score was calculated based on the FRAX algorithm. It should be noted that the latter is not specifically designed for cancer patients, which is why it does not account for Al intake as a risk factor; rather, it estimates the 10-year risk of bone fracture in postmenopausal women, with or without BMD assessment [58,60]. Based on the above, Coleman et al. published treatment guidelines for breast cancer patients at risk of aromatase inhibitor-associated bone loss (AIBL) and bone fracture. All women are recommended to engage in controlled physical exercise, such as walking, and take calcium and vitamin D3 supplements at a dose of no less than 1000 IU per day (preferably: 2000 IU per day) $[60,61]$. Many expert groups also emphasize the importance of bisphosphonates in AIBL prevention. Results of the Z-FAST study, which assessed the effectiveness of 5-year treatment with zoledronic acid, showed a statistically significant $(p \leq 0.0003)$ delay in the onset of bone loss [lumbar spine (LS) and total hip] in comparison with the baseline. Treatment time was not defined. Some authors recommend a maximum of 2 years, others emphasize that it should not extend beyond the duration of Al-based therapy. The guidelines of the ASCO (American Society of Clinical Oncology) do not specify the recommended treatment time either $[6,60]$.

Determined at reliability levels II and III, indications for the use of denosumab in AIBL prevention are not clear. "The Hormone Ablation Bone Loss Trial in Breast Cancer (HALT-BC)", which assessed its effectiveness in a group of 252 early breast cancer patients, demonstrated a statistically significant improvement in bone density $(7.6 \%, p=0.0001)$ in women treated with denosumab as compared to placebo. These results, however, should be interpreted with caution on account of the heterogeneity of the patient group (e.g. the intake of different Als, different treatment time). More promising findings were provided by "The ongoing Austrian Breast and Colorectal Cancer Study Group Trial-18" (ABCSG-18), which demonstrate the effectiveness of denosumab in improving bone density during Al adjuvant treatment $[55,60,61]$.

\section{Other hormonal treatment complications in women}

Tamoxifen-based hormonal therapy may increase the risk of endometrial cancer. A large study conducted by the NSABP estimated that the annual risk of disease equals 1.7 out of 1000 women (18), but that treatment benefits considerably outweigh the associated risk [62]. Swerdlow, on the other hand, showed that the risk of endometrial cancer in patients treated with tamoxifen equaled 2.4 (odds ratio $[\mathrm{OR}]=2.4 ; 95 \%$ confidence interval $[\mathrm{Cl}]=1.8-3.0$ ) and increased as a function of treatment length (five or more years); the results were statistically significant $p<0.001$ (OR $=3.6,95 \% \mathrm{Cl}=2.6-4.8)$. The risk was comparable in pre- and postmenopausal women $(\mathrm{OR}=2.0,95 \% \mathrm{Cl}=1.1-3.4)$ and in women under the age of 45 who have not undergone oophorectomy $(\mathrm{OR}=2.0,95 \% \mathrm{Cl}=1.2-3.5)$ [62].

Tamoxifen is also associated with a higher risk of thromboembolism. The BIG 1-98 study showed a statistically significant $(p<0.001)$ difference in the incidence of embolic complications in the group treated with the drug (3.5\%), as compared to the group that received letrozole (1.5\%) [63].

\section{Conclusion}

Hormonal therapy is the oldest targeted treatment method, allowing to increase survival rates not only in radical treatment but also in systemic prostate and breast cancer patients. Associated metabolic complications during its course, however, may contribute to higher cardiac disease mortality rates. The risk of osteoporosis and pathological fractures in men and women who undergo hormonal therapy is also greater than in the general population, and the presence of these complications considerably reduces the quality of life. For this reason, it is essential to keep in mind the importance of symptom prevention, early diagnosis, and treatment, with a view to improving both QoL parameters and patient survival. Patients should be advised to quit smoking, eat a proper diet, keep a healthy body weight and, as much as possible, maintain ongoing physical activity. All patients should also be regularly tested for blood pressure, lipid levels, and glycemia, and take vitamin D3 supplements in order to prevent osteoporosis. A correct diagnosis and treatment of treatment-related adverse effects allows to improve the quality of life in the patient group.

\section{Conflict of interest: none declared}

\section{Beata Jagielska, MD, PhD}

Department of Diagnostic Oncology and Cardioncology

Maria Skłodowska-Curie Memorial Cancer Centre

and Institute of Oncology

Roentgena St. 5

02-781 Warszawa, Poland

e-mail:bjagielska@coi.waw.pl

Received: 10 Mar 2016

Accepted: 31 Oct 2016

\section{References}

1. Iversen P, McLeod DG, See WA et al. Antiandrogen monotherapy in patients with localized or locally advanced prostate cancer: final results from the bicalutamide Early Prostate Cancer programme at a medium follow-up of 9.7 years. BJU Int 2010; 105: 1074-1081. 
2. Horwich A, Hugosson J, de Reijke T et al. Prostate cancer: ESMO Consensus Conference Guidelines 2012. Ann Oncol 2013; 24: 1141-1162.

3. NCCN Guidelines. Prostate Cancer, Version 3.2016

4. Loprinzi CL, Dueck AC, Khoyratty BS et al. A phase III randomized, double-blind, placebo-controlled trial of gabapentin in the management of hot flashes in men (NOOCB). Ann Oncol 2009; 20: 542-549.

5. Irani J, Salomon L, Oba R et al. Efficacy of venlafaxine, medroxyprogesterone acetate, and cyproterone acetate for the treatment of vasomotor hot flushes in men taking gonadotropin- releasing hormone analogues for prostate cancer: a double-blind, randomised trial. Lancet Oncol 2010; 11: 147-154.

6. Nelson CJ, Lee JS, Gamboa MC et al. Cognitive effects of hormone therapy in men with prostate cancer: a review. Cancer 2008; 113: 1097-1106.

7. Cherrier MM, Aubin S, Higano CS. Cognitive and mood changes in men undergoing intermittent combined androgen blockade for non-metastatic prostate cancer. Psychooncology 2009; 18: 237-247.

8. Lee M, Jim HS, Fishman M et al. Depressive symptomatology in men receiving androgen deprivation therapy for prostate: a controlled comparision. Psychooncology 2015; 24: 472-477.

9. Sieradzki J. Zespół metaboliczny. In: Interna Szczeklika: podręcznik chorób wewnętrznych. Kraków: Wydawnictwo Medycyna Praktyczna, 2012: 1360-1361.

10. Samper Ots PM, Garcia JL, Kavadoy YR et al. SIMBOSPROST: Prevalence of metabolic syndrome and osteoporosis in prostate cancer patients treated with radiotherapy and androgen deprivation therapy: a multicentre, cross-sectional study. Rep Pract Oncol Radiother 2015; 20: 370-376.

11. Morote J, Gomez-Caamano A, Alvarez-Ossorio JL et al. The metabolic syndrome and its components in patients with prostate cancer on androgen deprivation therapy. J Urol 2015; 193: 1963-1969.

12. Smith MR, Lee $H$, Nathan DM. Insulin sensitivity during combined androgen blockade for prostate cancer. J Clin Endocrine Metab 2006; 91: 1305-1308

13. Smith MR, Lee H, McGovern F et al. Metabolic changes during gonadotropin-releasing hormone agonist therapy for prostate cancer: differences from the classic metabolic syndrome. Cancer 2008; 112: 2188-2194.

14. Tsai HT, Keating NL, Van Den Eden SK et al. Risk of diabetes among patients receiving primary androgen deprivation therapy for clinically localized prostate cancer. J Urol 2015; 193: 1956-1962.

15. Basaria S, Muller DC, Carducci MA et al. Hyperglycemia and insulin resistance in men with prostate carcinoma who receive androgen-deprivation therapy. Cancer 2006; 106: 581-588.

16. Laaksonen D, Niskanen L, Punnonen $\mathrm{K}$ et al. Sex hormones, inflammation and the metabolic syndrome: a population-based study. Eur J Endocrin 2003; 149: 601-608.

17. Kohutek ZA, Weg ES, Pei X et al. Long-term impact of androgen-deprivation therapy on cardiovascular morbidity after radiotherapy for clinically localized prostate cancer. Urology 2016; 87: 146-152.

18. Davis MK, Rajala JL, Tydesley S et al. The prevalence of cardiac risk factors in men with localized prostate cancer undergone androgen deprivation therapy in British Columbia, Canada. J Oncol 2015; 2015: 820403.

19. Carnerio A, Sasse AD, Wagner AA et al. Cardiovascular events associated with androgen deprivation therapy in patients with prostate cancer: a systemic review and meta-analysis. World J Urol 2015; 33: 1281-1289.

20. D'Amico AV, Denham JW, Crook J et al. Influence of androgen suppression therapy for prostate cancer on the frequency and timing of fatal myocardial infarctions. J Clin Oncol 2007; 25: 2420-2425.

21. Levine GN, D'Amico AV, Berger P et al. Androgen-deprivation therapy in prostate cancer and cardiovascular risk: a science advisory [...]. CA Cancer J Clin 2010; 60: 194-201.

22. Saigal CS, Gore JL, Krupski TL et al. Androgen deprivation therapy increases cardiovascular morbidity in men with prostate cancer. Cancer 2007; 110: 1493-1500.

23. Keating NL, O'Malley AJ, Freedland SJ et al. Diabetes and cardiovascular disease during androgen deprivation therapy: observational study of veterans with prostate cancer. J Nat/ Cancer Inst 2010; 102 : 39-46.

24. Azvolinsky A. Androgen deprovation therapy-linked cardiovascular disease risk: still unresolved. J Natl Cancer Inst 2015: 107(9).pii: djv268. doi.:10.9093/jnci/djv268.

25. Bolla M, Van Tienhoven G, Warde P et al. External irradiation with or without long-term androgen suppression for prostate cancer with high metastatic risk: 10-year results of an EORTC randomised study. Lancet Oncol 2010; 11: 1066-1073.

26. Efstathiou JA, Bae K, Shipley WU et al. Cardiovascular mortality and duration of androgen deprivation for locally advanced prostate cancer: analysis of RTOG 92-02. Eur Urol 2008; 54: 816-823.
27. Nguyen PL, Je Y, Schutz FA et al. Association of androgen deprivation therapy with cardiovascular death in patients with prostate cancer: a meta-analysis of randomized trials. JAMA 2011; 306: 2359-2366.

28. Voog JC, Paulus R, Shipley WU et al. Cardiovascular mortality following short-term androgen deprivation in clinically localized prostate cancer: an analysis of RTOG 94-08. Eur Urol 2016; 69: 204-210.

29. Cheung AS, Pattison D, Bretherton I et al. Cardiovascular risk and bone loss in men undergoing androgen deprivation therapy for non-metastatic prostate cancer: implementation of standardized management guidelines. Andrology 2013; 1: 583-589.

30. Holmes-Walker DJ, Woo H, Gurney H et al. Maintaining bone health in patients with prostate cancer. Med J Aust 2006; 184: 176-179.

31. Morote J, Morin JO, Orsola A et al. Prevalence of osteoporosis during long-term androgen deprivation therapy in patients with prostate cancer. Urology 2007; 69: 500-504.

32. Saad F, Adachi JD, Brown JP et al. Cancer treatment-induced bone loss in breast and prostate cancer. J Cin Oncol 2008; 26: 5465-5476.

33. Serpa Neto A, Tobias-Machado M, Esteves MA et al. Bisphosphonate therapy in patients under androgen deprivation therapy for prostate cancer: a systematic review and meta-analysis. Prostate Cancer Prostatic Dis 2012; 15: 36-44.

34. Lipton A, Smith MR, Ellis GKet al. Treatment-induced bone loss and fractures in cancer patients undergoing hormone ablation therapy: efficacy and safety of denosumab. Clin Med Insights Oncology 2012; 6: 287-303.

35. Smith MR, Fallon MA, Lee $\mathrm{H}$ et al. Raloxifene to prevent gonadotropin-releasing hormone agonist-induced bone loss in men with prostate cancer: a randomized controlled trial. J Clin Endocrinol Metab 2004; 89: 3841-3846.

36. Smith MR, Morton RA, Barnette KG et al. Toremifene to reduce fracture risk in men receiving androgen deprivation therapy for prostate cancer. J Urol 2013; 189 (1 Suppl): S45-50.

37. Pieńkowski T. Znaczenie inhibitorów aromatazy w leczeniu chorych na raka piersi OncoReview 2012; 22: 173-181.

38. Senkus-Konefka E. Hormonalne leczenie nowotworów. Stan obecny i perspektywy. Nowa Medycyna 2000 (10) http://www.czytelniamedyczna.pl/1506, hormonalne-leczenie-nowotworow-stan-obecny-iperspektywy.html.

39. Sobstyl M, Tkaczuk-Włach J, Sobstyl J et al. Objawy uboczne stosowania tamoksyfenu i raloksyfenu. Przegląd Menopauzalny 2012; 11:250-253.

40. Wieczorek-Rutkowska M, Jassem J. Czynniki warunkujące skuteczność leczenia tamoksyfenem u chorych na raka piersi. Nowotwory J Oncol 2010; 60: 42-49.

41. Dehal SS, Kupfer D. CYP2D6 catalyzes tamoxifen 4-hydroxylation in human liver. Cancer Res 1997; 57: 3402-3406.

42. Mani C, Kupfer D. Cytochrome P-450-mediated activation and irreversible binding of the antiestrogen tamoxifen to proteins in rat and human liver: possible involvement of flavin-containing monooxygenases in tamoxifen activation. Cancer Res 1991; 51: 6052-6058.

43. Johnson MD, Zuo H, Lee KH i et al. Pharmacological characterization of 4-hydroxy-N-desmethyl tamoxifen, a novel active metabolite of tamoxifen. Breast Cancer Res Treat 2004; 85: 151-159.

44. Crewe HK, Ellis SW, Lennard MS et al. Variable contribution of cytochromes P450 2D6, 2C9 and 3A4 to the 4-hydroxylation of tamoxifen by human liver microsomes. Biochem Pharmacol 1997; 53: 171-178.

45. Desta Z, Ward BA, Soukhova NV et al. Comprehensive evaluation of tamoxifen sequential biotransformation by the human cytochrome P450 system in vitro: prominent roles for CYP3A and CYP2D6. J Pharmacol Exp Ther 2004; 310: 1062-1075.

46. Carpenter JS, Andrykowski MA, Cordova M et al. Hot flashes in postmenopausal women treated for breast carcinoma: prevalence, severity, correlates, management, and relation to quality of life. Cancer 1998; 82: 1682-1691.

47. Couzi RJ, Helzlsouer KJ, Fetting JH. Prevalence of menopausal symptoms among women with a history of breast cancer and attitudes toward estrogen replacement therapy. J Clin Oncol 1995: 13: 2737-2744.

48. Carpenter JS, Johnson D, Wagner L et al. Hot flashes and related outcomes in breast cancer survivors and matched comparison women. Oncol Nurs Forum 2002; 29: E16-25.

49. Avis NE. Breast cancer survivors and hot flashes: the search for nonhormonal treatments. J Clin Oncol 2008; 26: 5008-5010.

50. Kligman L, Yonus J. Management of hot flashes in women with breast cancer Curr Oncol 2010; 17: 81-86.

51. Jones KL, Buzdar AU. A review of adjuvant hormonal therapy in breast cancer. Endocr Relat Cancer 2004; 11: 391-406.

52. Fallowfield LJ, Bliss JM, Porter LS et al. Quality of life in the intergroup exemestane study: a randomized trial of exemestane versus continued 
tamoxifen after 2 to 3 years of tamoxifen in postmenopausal women with primary breast cancer. J Clin Oncol 2006; 24: 910-917.

53. Robert NJ, Goss PE, Ingle JN et al. Updated analysis of NCIC CTG MA.17 (letrozole vs placebo to letrozole vs placebo) post unblinding. $J$ Clin Oncol 2006; 24 (Suppl 18): 550. (Meeting Abstracts).

54. Stein KD, Jacobsen PB, Hann DM et al. Impact of hot flashes on quality of life among postmenopausal women being treated for breast cancer. J Pain Symptom Manage 2002; 19: 436-445.

55. DorjgochooT, Gu K, Kallianpur A et al. Menopausal symptoms among breast - libido cancer patients 6 months after cancer diagnosis: a report from the Shanghai Breast Cancer Survival Study. Menopause 2009; 16: 1205-1212.

56. Mourtis MJ, Bockermann I, de Vries EG et al.Tamoxifen effects on subjective and psychosexual well-being, in a randomised breast cancer study comparing high-dose and standard-dose chemotherapy. $\mathrm{Br} J$ Cancer 2002; 86: 1546-1550.

57. Juozaitytė E, Aleknavičiusb E, Janciauskiene R et al. Guidelines for diagnostics and treatment of aromatase inhibitor-induced bone loss in women with breast cancer: a consensus of Lithuanian medical oncologists, radiation oncologists, endocrinologists, and family medicine physicians. Medicina 2014; 50: 197-203.
58. Hadji P. Cancer treatment-induced bone loss in women with breast cancer. Bonekey Rep 2015; 4: 692.

59. Ratajczak M, Sakowicz-Burkiewicz M, Kuczkowski J et al. Rola receptora aktywatora jądrowego czynnika kappa B (RANKL) oraz osteoprotegeryny (OPG) w rozwoju zębopochodnych torbieli i ziarniniaków okołowierzchołkowych kości szczęki i żuchwy. Nowa Stomatol 2013 (4): 187-190.

60. Hadji P, Aapro MS, Body JJ et al. Management of aromatase inhibitorassociated bone loss in postmenopausal women with breast cancer: practical guidance for prevention and treatment. Ann Oncol 2011; 22: $2546-2255$.

61. Coleman R, Body J, Aapro M. Bone health in cancer patients: ESMO Clinical Practice Guidelines. Ann Oncol 2014; Suppl 3: iii124- iii137.

62. Fisher B, Costantino JP, Redmond CK et al. Endometrial cancer in tamoxifen-treated breast cancer patients, findings from the National Surgical Adjuvant Breast and Bowel Project (NSABP) B-14. J Nat/ Cancer Inst 1994; 86: 527-537.

63. Swerdlow AJ, Jones ME; British Tamoxifen Second Cancer Study Group. Tamoxifen treatment for breast cancer and risk of rndometrial cancer: a case — control study. J Nat/ Cancer Inst 2005; 97: 375-384. 